\title{
Familial bulbospinal neuronopathy with optic atrophy: a distinct entity
}

\author{
Guillermo Paradiso, Federico Micheli, Ana Lía Taratuto, Ignacio Casas Parera
}

\begin{abstract}
A 61 year old woman and her 58 year old brother presented with the clinical picture of late onset progressive bulbar and spinal muscular atrophy with family history of involvement in successive generations. The sister also had optic neuropathy and the brother developed diabetes mellitus and sex hormone abnormalities. Neurophysiological and histopathological studies showed a pattern of motor and sensory neuronopathy. There was no abnormal expansion of CAG repeats in the androgen receptor gene. This family seems to have a previously unrecognised entity with the bulbospinal neuronopathy phenotype.
\end{abstract}

(F Neurol Neurosurg Psychiatry 1996;61:196-199)

Keywords: bulbospinal neuronopathy; genetics; optic neuropathy

The bulbospinal neuronopathy phenotype has been invariably associated with a well defined condition characterised by $\mathrm{X}$ linked recessive inheritance, adult onset weakness, and atrophy involving the proximal aspect of all four limbs and bulbar muscles, accompanied by painful cramps, generalised fasciculation, and endocrine disturbances not threatening the normal life span. ${ }^{1}$ It is caused by androgen receptor gene mutations at the proximal long arm of the X chromosome. ${ }^{2}$

Here we report the clinical features of a male patient with the full picture of $\mathrm{X}$ recessive bulbospinal neuronopathy (X-RBSN) and his elder sister with the neurological manifestations of X-RBSN who, in addition, had a progressive optic neuropathy. Neither of the patients had an expansion of the CAG repeat in the androgen receptor gene.

\section{Case reports}

PATIENT 1, III 2

This 61 year old woman developed progressive painful cramps in her thighs and upper arms, stiffness moderately impairing her gait, and increased sweating when she was in her early 30s. Painful muscle spasms were exacerbated by fatigue and often awakened her at night, fixing her ankles, elbows, and wrists in flexed position for several minutes. Mild hypothyroidism secondary to immunological thyroiditis was diagnosed and successfully treated at age 41. Progressive visual loss became evident at the age of 54 and three years later she noticed difficulties in climbing stairs, rising from a low chair, and frequent choking triggered by swallowing solid food. Over the past years stiffness and cramp severity diminished and sweating returned to normal but weakness progressed along with visual impairment; currently she can no longer comb her hair and is unable to identify faces.

She had wasting of the shoulder and pelvic girdle muscles (fig 1) associated with waddling gait and generalised myokymia. Fundus oculi disclosed pale optic disks, and visual acuity was reduced to shape discrimination. Facial and lingual muscles showed myokymia without overt weakness or atrophy. The velum palatinum elevated well in the midline. There

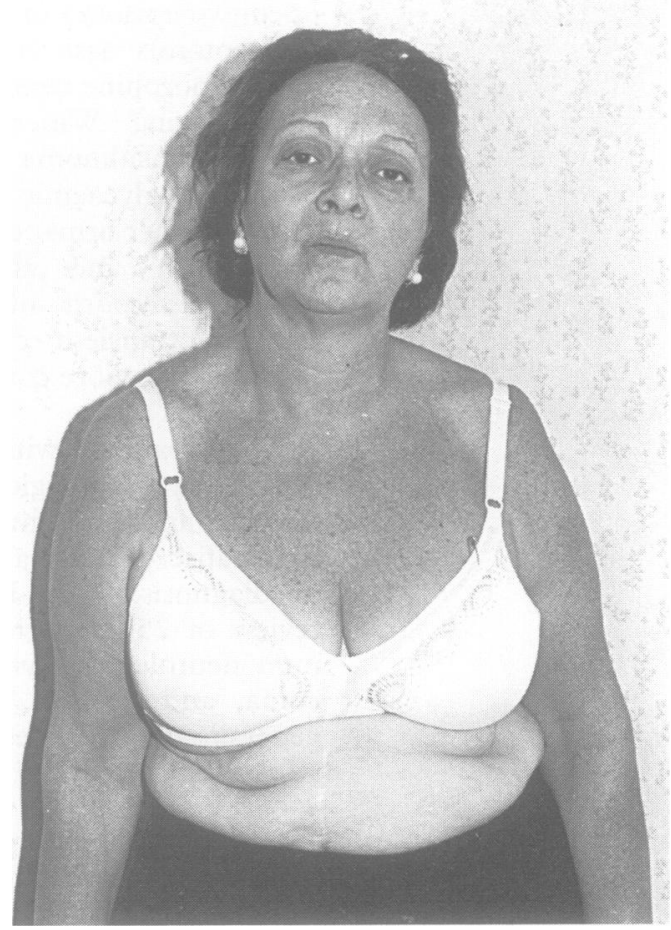

Figure 1 Patient 1 (III 2), a 61 year old woman showing severe atrophy of shoulder girdle muscles (with permission). 


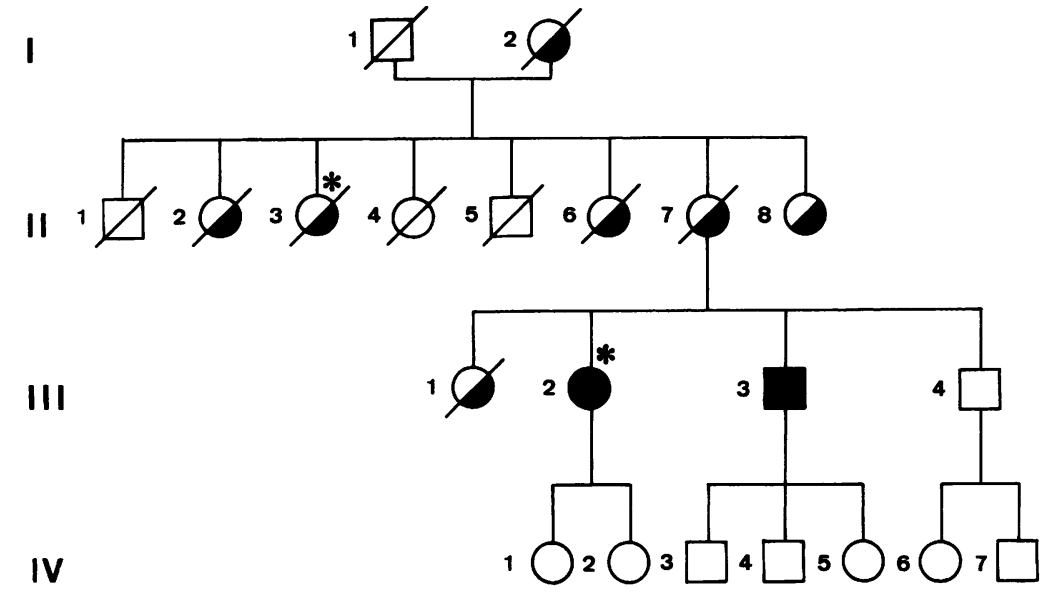

Figure 2 Pedigree of the family. Square = male; circle = female; oblique line $=$ deceased; solid symbol = propositi; open symbol = unaffected; half shaded symbol = affected by history; asterisk = visual impairment.

was severe weakness of the proximal aspects of both upper and lower limbs, but distal strength was fairly well preserved. Stiffness and percussion myotonia were absent although there was mild slowing of grip relaxation. Muscle tone was normal and plantar reflexes were flexor. Deep tendon reflexes were lacking, and there was no sensory impairment.

PATIENT 2, III 3

This 58 year old man, the younger brother of patient 1 , had a long history of postural hand tremor. At the age of 30 he developed progressive generalised stiffness associated with occasional painful cramps in his thighs. During the next years cramps became more frequent and prolonged, lasting several minutes. They were unrelated to fatigue, temperature, or exertion and often awakened him at night inducing painful forced flexion or extension postures in his arms and feet. On developing a reduction in sexual performance at age 50 , mild diabetes mellitus was diagnosed. Three years later he developed progressive difficulties in climbing stairs and swallowing solid food, with frequent choking episodes and slurring of speech. At present, cramps have become sporadic, but he is unable to rise from a chair on his own and can barely lift his arms above head level.

He was dysarthric and showed widespread myokymia, shoulder and pelvic girdle muscle wasting, and a waddling gait. Fundi oculi were normal and visual fields full. Facial muscles were weak and palatal motility was slightly impaired. Symmetric weakness in the proximal muscles of all four limbs associated with mildly reduced strength in foot dorsiflexors was evident. Deep tendon reflexes were absent and there was no sensory deficit. No abnormalities were detected in muscle tone and plantar reflexes. A fine postural tremor was present on outstretched hands.

Figure 2 shows the family pedigree. The reported patients (III 2, III 3) gave reliable information about other members of the family. Members I 2, II 2, II 3, II 6, II 7, II 8, and III 1 all had cramps, stiffness, weakness, dysphagia, and waddling gait which they described as the "family hallmark", from the fourth decade of life. Members I 2, II 2, II 3,and II 6 died at the ages of $75,75,77$, and 80 respectively, all had used walking sticks by the early 8th decade, and were confined to wheelchairs towards the end of their lives; II 3 additionally developed progressive visual impairment in her early 60 s and became blind shortly before her death. Member II 7 died at the age of 62 because of colonic cancer, II 8 is alive, aged 85 and is confined to a wheelchair. She refused to be examined. Member III 1 died at 53 after cardiac stroke, five years after a diagnosis of diabetes. Members IV 3, IV 4, and IV 5 aged 24,23 , and 19 respectively, were clinically and neurophysiologically examined and no abnormalities were detected.

\section{Investigations}

Routine blood count, urea, creatinine, electrolytes, and electrophoretic and immunoelectrophoretic studies of protein were normal in both patients. Relevant laboratory findings were as follows (normal values in parentheses): patient 1 , creatine kinase $120 \mathrm{UI} / 1(0-80$ $\mathrm{UI} / \mathrm{l})$, cholesterol $318 \mathrm{mg} / \mathrm{dl}$ (140-250 mg/dl), triglycerides $358 \mathrm{mg} / \mathrm{dl}(40-170 \mathrm{mg} / \mathrm{dl})$, glycaemia $86 \mathrm{mg} / \mathrm{dl}(70-110 \mathrm{mg} / \mathrm{dl}$, oral glucose tolerance test was normal), antithyroglobulin antibodies $1 / 400(\leqslant 1 / 100)$, antimicrosomal fraction antibodies $1 / 6400(\leqslant 1 / 100)$, T4 $5 \cdot 2$ $(\mu \mathrm{g} / \mathrm{dl} \quad(5.5-12.5 \mu \mathrm{g} / \mathrm{dl})$, TSH $8.4 \mu \mathrm{UI} / \mathrm{ml}$ $(<6.5 \mu \mathrm{UI} / \mathrm{l}), \quad$ LH $\quad 13.5 \mathrm{mUI} / \mathrm{ml} \quad(20-70$ $\mathrm{mUI} / \mathrm{ml})$, testosterone $0.13 \mathrm{ng} / \mathrm{ml} \quad(0.3-1.0$ $\mathrm{ng} / \mathrm{ml}$ ); patient 2 , creatine kinase $147 \mathrm{UI} / 1$ (0-80 UI/L), cholesterol $206 \mathrm{mg} / \mathrm{dl}$ (140-250 $\mathrm{mg} / \mathrm{dl})$, triglycerides $1108 \mathrm{mg} / \mathrm{dl} \quad(40-170$ $\mathrm{mg} / \mathrm{dl})$, glycaemia $152 \mathrm{mg} / \mathrm{dl}(70-110 \mathrm{mg} / \mathrm{dl})$, FSH $44 \mathrm{mUI} / \mathrm{ml}(1 \cdot 7-7 \cdot 8 \mathrm{mUI} / \mathrm{ml})$, oestradiol $(>200 \mathrm{pg} / \mathrm{ml}(10-60 \mathrm{pg} / \mathrm{ml}), \mathrm{LH}(>40 \mathrm{mUI} /$ $\mathrm{ml}(4 \cdot 7-11 \mathrm{mUI} / \mathrm{ml})$, basal testosterone $4 \cdot 0$ $\mathrm{ng} / \mathrm{ml}(3 \cdot 0-9 \cdot 0 \mathrm{ng} / \mathrm{ml})$, and after stimulation with HCG prophase 4000 the maximal increase ( 48 hours, $7 \cdot 3 \mathrm{ng} / \mathrm{ml}=66 \%$ ) was below the normal range $(80-100 \%)$.

Nerve conduction studies and EMG as well as muscle and nerve biopsy were performed in both patients, showing essentially the same findings so that henceforth they are described together.

Concentric needle EMG showed motor unit-like spontaneous potentials firing rhythmically or semirhythmically at variable frequency rates from less than $1 \mathrm{c} / \mathrm{s}$ up to $60 \mathrm{c} / \mathrm{s}$. Bursts usually lasted several seconds, but sometimes their duration was several minutes. Myokymic bursts with decreasing amplitude and frequency were also seen. Spontaneous potentials could not be activated voluntarily and neither percussion nor ischaemia influenced the firing pattern. Voluntarily activated motor unit potentials showed a typical chronic neurogenic pattern of prolonged duration, increased amplitude, and frequent polyphasia; the full effort recruitment pattern was reduced. Spontaneous activity after maximal effort was reinforced in patient 1 . Motor nerve conduction study was normal, whereas sensory nerve examination showed normal or 
mildly decreased conduction velocities and reduced amplitudes of the compound action potentials indicating, in conjunction with EMG findings, chronic axonal motor and sensory peripheral neuropathy.

Histopathological examination of the vastus medialis muscles showed mild variation in fibre size with several small angulated fibres intensely stained with NADH-TR and nonspecific esterase, a few targetoid fibres, and type grouping, consistent with chronic denervation; no abnormal cytochrome oxidase activity or ragged red fibres were present. Ultrastructural examination of muscle (patient 2) disclosed normal mitochondrial configuration.

Light microscopy of the sural nerve disclosed prominent epineurial and endoneurial fibrosis and obvious loss of myelinated fibres. Teased fibre preparations showed variation in internodal length, uniformly short internodal lengths, and axonal degeneration as well as segmental demyelination. Ultrastructural investigation confirmed the severe depletion of myelinated fibres and generalised increase of endoneurial collagen. Several large myelinated fibres showed overt increase in myelin thickness compared with axonal diameter, with infolding or outpouching of myelin sheaths. A few thinly myelinated large diameter axons were also seen but onion bulbs and axonic clusters were not evident. The karyotype was normal in patient 1 . The DNA examination performed at the Institute of Neurology of the National Hospital of London failed to show androgen receptor gene mutations in the following members of the family: III 2 (patient 1), III 3 (patient 2), IV 2, and IV 5.

\section{Discussion}

We describe a sister and brother with progressive proximal muscular weakness and atrophy, prominent cramps, widespread myokymia, stiffness, dysphagia, and dysarthria, with onset in the fourth decade of life. Muscle stiffness, cramps, and delayed muscular relaxation were prominent features in the decade after onset, vanishing as muscular atrophy and weakness progressed. Neurophysiological and histopathological findings are compatible with primary involvement of both peripheral motor and sensory neurons.

In addition, the sister showed progressive optic atrophy, immunological thyroiditis, and dyslipaemia, and the brother presented postural tremor with onset in adolescence, mild maturity onset diabetes, type IV dyslipaemia, and abnormalities in serum sex hormone concentrations with sexual impotence.

The absence of abnormal CAG repeats in the androgen receptor gene of the two patients and their daughters indicates that our patients have a previously unrecognised entity with the bulbospinal neuronopathy phenotype.

The family pedigree showing involvement of successive generations suggests dominant inheritance; nevertheless exclusive maternal transmission has been recorded. Therefore mitochondrial DNA alterations cannot be ruled out even when careful pathological examination did not disclose changes consistent with mitochondrial disease.

On clinical grounds the two major differences between our family and the X-RBSN are female involvement and progressive optic atrophy in our family. In addition, our patients showed more pronounced spontaneous motor unit activity resulting in severe cramps, contractures, and delayed muscle relaxation. Although mild EMG and biopsy abnormalities have been reported in female carriers with X$\mathrm{RBSN}^{3}$ none of them presented with the full clinical picture seen in our female patient.

Until recently, diagnosis of spinal muscular atrophy has been largely focused on its differentiation from muscular dystrophy by the clinical presence of fasciculations as well as the EMG and muscle biopsy neurogenic pattern whereas neurophysiological and histopathological studies of sensory nerves have hardly ever been performed. Consequently classifications have included forms with late onset, proximal involvement, and dominant trait, comprising "pseudomyopathic", 4 scapuloperoneal, ${ }^{5}$ and facioscapulohumeral ${ }^{6}$ varieties, in which bulbar compromise is rare and optic atrophy and endocrinological abnormalities are not described, as well as the bulbospinal type in which life expectancy is clearly shortened. ${ }^{7.9}$

On the other hand, cases of dominantly inherited motor and sensory neuropathy associated with a single distinct complication such as optic atrophy, ${ }^{10}$ postural tremor, ${ }^{11}$ or continuous muscle fibre activity ${ }^{1213}$ have been reported, but they share the classic picture of the Charcot-Marie-Tooth syndrome, including early onset.

In 1965, before Kennedy's description, Tsukagoshi et al reported five male patients with the typical features of X-RBSN, one of whom (patient 4) had an affected mother, ${ }^{14}$ a finding that probably led them to rule out $\mathrm{X}$ recessive inheritance in all their patients. Although no conclusive evidence is available, this family presumably represents the first description of this hereditary bulbospinal neuronopathy affecting both males and females.

We are grateful to the late Professor A Harding who generously performed the DNA analysis at the Institute of Neurology, National Hospital, London.

1 Kennedy WR, Alter M, Sung JH. Progressive proximal spinal and bulbar muscular atrophy of late onset. A sexlinked recessive trait. Neurology 1968 18:671-80.

2 La Spada AR, Wilson EM, Lubalm DB, Harding AE, Fischbeck KH. Androgen receptor gene mutations in Xlinked spinal and bulbar muscular atrophy. Nature 1991 352:77-9.

3 Sobue G, Doyu M, Kachi T, et al. Subclinical phenotypic expressions in heterozigous females of $X$-linked recessive bulbospinal neuronopathy. F Neurol Sci 1993;117:74-8.

4 Finkel N. A forma pseudomiopática tardia da atrofia muscular progressiva heredo-familial. Arquinos de NeuroPsiquiatria 1962:4:307-22.

5 Kaeser HE. Scapuloperoneal muscular atrophy. Brain 1965;88:407-18.

6 Fenichel GM, Emery ES, Hunt P. Neurogenic atrophy simulating facioscapulohumeral dystrophy. A dominant form. Arch Neurol 1967;17:257-60.

7 Namba T, Aberfeld DC, Grob D. Chronic proximal spinal muscular atrophy. $\mathcal{I}$ Neurol Sci 1970;11:401-23.

8 Zatz M, Penha-Serrano C, Frota-Pessoa O, Klein D. A malignant form of neurogenic muscular atrophy in malignant form of neurogenic muscular atrophy in
adults, with dominant inheritance. $\mathcal{F}$ Génét Hum $1971 ; 19$ : adults, with 
9 Schiffer D, Brignolio F, Chiò A, Giordana MT, Migheli A. Clinical-anatomic study of a family with bulbo-spinal

10 Milhorat AT. Studies in diseases of muscle. XIV. Progressive muscular atrophy of peroneal type associated Progressive muscular atrophy of peroneal type associated
with atrophy of the optic nerves; report on a family. Arch with atrophy of the optic nerves; rep
Neurol Psychiatry 1943;50:279-87.

11 Dyck PJ, Lambert EH. Lower motor and primary sensory neuron diseases with peroneal muscular atrophy. INeurologic, genetic, and electrophysiologic findings in hereditary polyneuropathies. Arch Neurol 1968;18:603-18.

12 Gamstorp I, Wohlfart G. A syndrome characterized by myokymia, muscular wasting and increased perspiration. Acta Psychiat Neurol Scand 1959;34:181-94.

13 Lance JW, Burke D, Pollard J. Hyperexcitability of motor and sensory neurons in neuromyotonia. Ann Neurol and sensory ne

14 Tsukagoshi $H$, Nakanishi $T$, Kondo $K$, Tsubaki $T$. Hereditary proximal neurogenic muscular atrophy in adult. Arch Neurol 1965;12:597-603.

\section{NEUROLOGY IN LITERATURE}

\section{Disorders of gait}

Mrs Gamp was "a little screwed" most of the time. Her cerebellar ataxia would eventually be permanent unless she became abstinent, an unlikely development considering her track record. Baron de Charles seems to have had cerebellar problems in the limbs, as does $\mathrm{Mr}$ Dolls in Our mutual friend. The basis for Phil's gait disorder, described in Bleak House, is not clear from Dickens' description. Perhaps he had a unilateral cerebellar syndrome. Clym Yeobright's gait, in The return of the native, was probably a familial characteristic, and not pathological. Mrs Yeobright identified her son by his gait, as it resembled that of her husband.

Charles Dickens, 1843-4, Martin Chuzzlewit Even after this precaution, she walked so unsteadily as to attract the compassionate regards of divers kindhearted boys, who took the liveliest interest in her disorder; and in their simple language, bade her be of good cheer, for she was "only a little screwed".

Charles Dickens, 1853, Bleak House

He has a curious way of limping round the gallery with his shoulder against the wall and tacking off at objects he wants to lay hold of instead of going straight to them, which has left a smear all around the four walls, conventionally called "Phil's Mark".

Charles Dickens, 1864-5, Our mutual friend

A judiciously small quantity of the spirit was given him in a wine glass, and he began to convey it to his mouth, with all kinds of falterings and gyrations on the road.

Thomas Hardy, 1878, The return of the native Suddenly she was attracted to his individuality by observing peculiarities in his walk. It was a gait she had seen somewhere before: and the gait revealed the man to her, as the gait of Ahimaaz in the distant plain made him known to the watchman of the king.

Marcel Proust, 1927, Remembrance of things past Time regained

Perhaps also there was in the movements of the Baron that lack of co-ordination which follows upon maladies of the spinal column and the brain, so that his gestures went beyond anything that he intended.

G D PERKIN

Regional Neurosciences Centre, Charing Cross Hospital, Fulham Palace Road,
London W6 $8 R F$, UK 